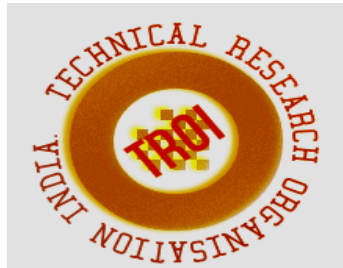

\title{
SMART POWER GENERATION WITH RENEWABLE
} ENERGY SOURCES

\author{
Hari Prasad ${ }^{1}$, Lakshmipathi .S ${ }^{2}$, Nelson John Antony .D ${ }^{3}$, Vishwas .C ${ }^{4}$, Subhashini $\mathrm{S}^{5}$ \\ ${ }^{1,2,3,4-}$ Students, Dr.TTIT, KGF, ${ }^{5-}$ Asst Prof, Dr.TTIT, KGF,
}

\begin{abstract}
Renewable energy sources (RES) used in smart city for power generation systems are energy supply toward smarter and more sustainable cities. However, their proper integration as new infrastructures of the smart city (SMCT) requires understanding the SMCT architecture and promoting changes to the existing regulation, business models, and power grid topology and operation, constituting a new challenging energy supply paradigm.
\end{abstract}

This technology addresses the use of renewable energy systems on smart city, oriented to distributed generation (DG) for households or districts, integrated in an SMCT. In this context, the main renewable energies and companion technologies are reviewed, and their profitability investigated to highlight their current economic feasibility. A simplified architecture for SMCT development is presented, consisting of three interconnected layers, the integration and impact of distributed renewable energy generation and storage technologies in this architecture is analyzed. Special attention is paid to the grid topology for their technical and efficient integration, and to the business models for facilitating their economic integration and feasibility.

Index Terms: Solar Energy, Wind Energy, Thermo Electric Generator, Piezo Electric Generator

\section{INTRODUCTION}

Renewable energy is energy generated from natural resources such as sunlight, wind, rain, tides, and geothermal heat, which are renewable (naturally replenished). In 2006, about 18\% of global final energy consumption came from renewable, with $13 \%$ coming from traditional biomass, such as wood-burning and 3\% from hydroelectricity[1]. New renewable (small hydro, modern biomass, wind, solar, geothermal, and bio fuels) accounted for $2.4 \%$ and are growing very rapidly. The share of renewable in electricity generation is around $18 \%$, with $15 \%$ of global electricity coming from hydroelectricity and $3.4 \%$ from new renewable.

Wind power is growing at the rate of $30 \%$ annually, with a worldwide installed capacity of 121,000 megawatts (MW) in 2008, and is widely used in European countries and the United States[3]. The annual manufacturing output of the photovoltaics industry reached 6,900 MW in 2008, and photovoltaic (PV) power stations are popular in Germany and Spain.

Solar thermal power stations operate in the USA and Spain, and the largest of these is the 354 MW power plant in the Mojave Desert. The world's largest geothermal power installation is the geysers in California, with a rated capacity of $750 \mathrm{MW}$. Brazil has one of the largest renewable energy programs in the world, involving production of ethanol fuel from sugar cane, and ethanol now provides $18 \%$ of the country's automotive fuel. Ethanol fuel is also widely available in the USA.

While most renewable energy projects and production is large-scale, renewable technologies are also suited to small off-grid applications, sometimes in rural and remote areas, where energy is often crucial in human development[4-5].Kenya has the world's highest household solar ownership rate with roughly 30,000 small (20-100 watt) solar power systems sold per year.

Renewable energy resources exist over wide geographical areas, in contrast to other energy sources, which are concentrated in a limited 
number of countries. Rapid deployment of renewable energy and energy efficiency is resulting in significant energy security, climate change mitigation and economic benefits. The results of a recent review of the literature concluded that as greenhouse gas (GHG) emitters begin to be held liable for damages resulting from GHG emissions resulting in climate change, a high value for liability mitigation would provide powerful incentives for deployment of renewable energy technologies. In international public opinion surveys there is strong support for promoting renewable sources such as solar power and wind power. At the national level, at least 30 nations around the world already have renewable energy contributing more than 20 percent of energy supply. National renewable energy markets are projected to continue to grow strongly in the coming decade and beyond. Some places and at least two countries, Ireland and Norway generate all their electricity using renewable energy already and many other countries have the set a goal to reach $100 \%$ renewable energy in the future. For example, in Denmark the government decided to switch the total energy supply (electricity, mobility and heating or cooling) to $100 \%$ renewable energy by 2050 .

While many renewable energy projects are large-scale, renewable technologies are also suited to rural and remote areas and developing countries, where energy is often crucial in human development. Former United Nations Secretary-General Ban Ki-moon has said that renewable energy has the ability to lift the poorest nations to new levels of prosperity. As most of renewable provide electricity, renewable energy deployment is often applied in conjunction with further electrification, which has several benefits: Electricity can be converted to heat (where necessary generating higher temperatures than fossil fuels), can be converted into mechanical energy with high efficiency and is clean at the point of consumption. In addition to that electrification with renewable energy is much more efficient and therefore leads to a significant reduction in primary energy requirements, because most renewable don't have a steam cycle with high losses (fossil power plants usually have losses of 40 to $65 \%$ ).
Wind-generated electricity met nearly $4 \%$ of global electricity demand in 2015, with nearly $63 \mathrm{GW}$ of new wind power capacity installed. Wind energy was the leading source of new capacity in Europe, the US and Canada and the second largest in China. In Denmark, wind energy met more than $40 \%$ of its electricity demand while Ireland, Portugal and Spain each met nearly $20 \%$.

\section{History of Renewable energy}

Prior to the development of coal in the mid19th century, nearly all energy used was renewable. Almost without a doubt the oldest known use of renewable energy, in the form of traditional biomass to fuel fires, dates from 790,000 years ago. Use of biomass for fire did not become common place until many hundreds of thousands of years later, sometime between 200,000 and 400,000 years ago. Probably the second oldest usage of renewable energy is harnessing the wind in order to drive ships over water[5]. This practice can be traced back some 7000 years, to ships in the Persian Gulf and on the Nile. Moving into the time of recorded history, the primary sources of traditional renewable energy were human labor, animal power, water power, wind, in grain crushing windmills, and firewood, a traditional biomass. A graph of energy use in the United States up until 1900 shows oil and natural gas with about the same importance in 1900 as wind and solar played in 2010.

In the 1860s and '70s there were already fears that civilization would run out of fossil fuels and the need was felt for a better source. In 1873 Professor Augustin Mouchot .The time will arrive when the industry of Europe will cease to find those natural resources, so necessary for it. Petroleum springs and coal mines are not inexhaustible but are rapidly diminishing in many places. Will man, then, return to the power of water and wind? Or will he emigrate where the most powerful source of heat sends its rays to all? History will show what will come.

In 1885, Werner von Siemens, commenting on the discovery of the photovoltaic effect in the solid state, wrote: In conclusion, I would say that however great the scientific importance of this discovery may be, its practical value will be no less obvious when we reflect that the supply of solar energy is both without limit and without 
cost, and that it will continue to pour down upon us for countless ages after all the coal deposits of the earth have been exhausted and forgotten[6].

In 1821, Thomas Johann See beck rediscovered that a thermal gradient formed between two dissimilar conductors can produce electricity. At the heart of the thermoelectric effect is the fact that a temperature gradient in a conducting material results in heat flow; this results in the diffusion of charge carriers. The flow of charge carriers between the hot and cold regions in turn creates a voltage difference. In 1834, Jean Charles Athanase Peltier discovered the reverse effect that running an electric current through the junction of two dissimilar conductors could, depending on the direction of the current, cause it to act as a heater or cooler.

The first demonstration of the direct piezoelectric effect was in 1880 by the brothers Pierre Curie and Jacques Curie. They combined their knowledge of pyro electricity with their understanding of the underlying crystal structures that gave rise to pyro electricity to predict crystal behavior, and demonstrated the effect using crystals of tourmaline, quartz, topaz, cane sugar

and rochelle salt (sodium potassium tartrate tetrahydrate). Quartz and Rochelle salt exhibited the most piezoelectricity.

\section{Need For Smart Power Generation.}

Alternative energy is any energy source that is an alternative to fossil fuel. These alternatives are intended to address concerns about fossil fuels, such as its high carbon dioxide emissions, an important factor in globalwarmingmarineenergy, hydroelectric, wind, geothermal and solar power are all alternative sources of energy. The nature of what constitutes an alternative energy source has changed considerably over time, as have controversies regarding energy use. Because of the variety of energy choices and differing goals of their advocates, defining some energy types as "alternative" is considered very controversial.

There is a current global need for clean and renewable energy sources. Fossil fuels are non-renewable and require finite resources, which are dwindling because of high cost and environmentally damaging retrieval techniques.
So, the need for cheap and obtainable resources is greatly needed.

There is a current global need for clean and renewable energy sources. Fossil fuels are nonrenewable and require finite resources, which are dwindling because of high cost and environmentally damaging retrieval techniques[7]. So, the need for cheap and obtainable resources is greatly needed. An efficient and more feasible alternative option is solar energy.

Human activity is overloading our atmosphere with carbon dioxide and other global warming emissions. These gases act like a blanket, trapping heat. The result is a web of significant and harmful impacts from stronger, more frequent storms to drought sea level rise and extinction.

In contrast, most renewable energy sources produce little to no global warming emissions. Even when including "life cycle" emissions of clean energy (ie, the emissions from each stage of a technology's life-manufacturing, installation, operation, decommissioning), the global warming emissions associated with renewable energy are minimal.

\section{Future of Smart Power Generation using Renewable Energy Resources}

The smart power generation is working towards producing $40 \%$ of its installed electricity capacity by 2030 from non-fossil fuels. This would lead to a significant shift from coal-based power generation to renewable energy sources. Renewable will overtake gas and then oil by 2020 as the second largest source of energy production[4]. The Renewable Electricity Futures Study found that an 80 percent renewable future is feasible with currently available technologies, including wind turbines, solar photovoltaics, concentrating solar power, biopower, geothermal, and hydropower.

That's faster than other renewable energy sources like solar and hydro-power. The price of wind-generated energy is currently competitive with fossil fuels, Guinness says. ... Today about $0.1 \%$ of the world's energy comes from solar power, most of it using photovoltaic cells.

There are several important reasons that make renewable energy extremelyimportant for 


the future of our society. ...

using renewable energy instead of fossil fuels we would significantly decrease the current levels of greenhouse gas emissions, and this would have positive environmental impact for our entire planet.

That's about the same amount of energy in 10 trillion trillion billion megaton bombs! These explosions generate beams of highenergy radiation, called gamma-ray bursts (GRBs), which are considered by astronomers to be the most powerful thing in the universe.

There are several important reasons that make renewable energy extremely important for the future of our society [3]. Renewable energy still has a long way to go in order to replace fossil fuels and become primary source of energy consumption but things have been lately definitely moving in the right direction. But let us focus here about the future impact of renewable energy on our society.

Positive environmental impact is certainly one of the most important reasons. Fossil fuels when burn, create harmful greenhouse gas emissions and our planet is already feeling the impact of climate change. By using renewable energy instead of fossil fuels we would significantly decrease the current levels of greenhouse gas emissions, and this would have positive environmental impact for our entire planet [9].

\section{What is Smart Power Generation?}

President Obama has called for the United States to secure $25 \%$ of our electricity from clean, renewable resources by 2025. And yet, renewable sources other than hydropower still provide only about 5\%of the electricity supply for our grid. What's holding us back? Our grid is partly to blame [10]. The physical reality is that the wind, solar, and geothermal resources are usually located in remote places, while much of the power demand is in urban areas. Like the interstate highway System, we need an electric superhighway that provides infrastructure for electricity to get from North Dakota to New York City easily and efficiently[9]. Geography issues aside, the current grid has difficulty accommodating variable sources of power like wind and solar energy, the fastest-growing sources of renewable power on the grid. As these resources begin to supply increasing percentages of power to the grid, integrating them into grid operations will become increasingly difficult.

The Smart Grid will be able to make better use of these energy resources[4]. It will give grid operators new tools to reduce power demand quickly when wind or solar power dips, and it will have more energy storage capabilities to absorb excess wind and solar power when it isn't needed, then to release that energy when the wind and solar power dips. In effect, energy storage will help to smooth out the variability in wind and solar resources, making them easier to use. Building an electric superhighway can also help solve the problem, as it will help to ship the power to where it is needed. Studies have shown that connecting wind resources from a diversity of geographic locations helps to balance out fluctuations in wind power [11]. In other words, when the wind isn't blowing in Iowa, in may be blowing in North Dakota or Wyoming. Having such geographically diverse wind resources on a single electric superhighway will result in a more steady supply of wind power to the nation's power grid, making it easier for grid operators to make full use of this resource.

Energy is an indispensable factor for the economic growth and development of a country. Energy consumption is rapidly increasing worldwide. To fulfill this energy demand, alternative energy sources and efficient utilization are being explored. Various sources of renewable energy and their efficient utilization are comprehensively reviewed and presented in this paper. Also the trend in research and development for the technological advancement of energy utilization and smart grid system for future energy security is presented.

Results show that renewable energy resources are becoming more prevalent as more electricity generation becomes necessary and could provide half of the total energy demands by 2050. To satisfy the future energy demand, the smart grid system can be used as an efficient system for energy security. The smart grid also delivers significant environmental benefits by conservation and renewable generation integration [12]. 


\section{LITERATURE SURVEY}

1. The Impacts of Storing Solar Energy in the home to reduce reliance on the utility by Robert L. Fares and Michael E. Webber Proceedings of the IEEE: Published: 30 January 2017

There has been growing interest in using energy storage to capture solar energy for later use in the home to reduce reliance on the traditional utility. However, few studies have critically assessed the trade-os associated with storing solar energy rather than sending it to the utility grid, as is typically done today. Here we show that a typical battery system could reduce peak power demand by $8-32 \%$ and reduce peak power injections by 5-42\%, depending on how it operates. However, storage ine-ciencies increase annual energy consumption by 324 $591 \mathrm{kWh}$ per household on average. Furthermore, storage operation indirectly increases emissions by 153-303 kg CO2, 0.03$0.20 \mathrm{~kg} \mathrm{SO} 2$ and $0.04-0.26 \mathrm{~kg}$ NOx per Texas household annually. Thus, home energy storage would not automatically reduce emissions or energy consumption unless it directly enables renewable energy.

2. Solar Energy and PV Systems in Smart Cities by Daniele Menniti ${ }^{1}$, Angel A. Bayod-Rújula ${ }^{2}$, Alessandro Burgio ${ }^{3}$, Diego A. L. García ${ }^{4}$ Proceedings of the IEEE Published 9 July 2017

A PV system on the rooftop is an easy and cost-effective way which allows consumers to independently meet a part of own electricity need. From an economic and financial perspective, consumers reduce the electricity bill and save money. These savings can be reinvested in actions aimed at the increase in energy efficiency, so triggering a worthy process of improvement. From a social perspective, consumers exploit renewable energy sources, so contributing to the environmental preservation by reducing the greenhouse gas emissions.

The opportunities described above are evidently reserved to those users who have ample space for installing a PV system; on the contrary, users who live in apartment buildings in the cities are excluded. For the latter category, smart cities may represent a solution. Indeed, smart cities can offer to all citizen the same opportunities in the pair of renewable energy source exploitation and sustainable development. As an example, citizens living in a rural area have large roofs; their existing or new PV plants can be oversized with respect to the local demand, and the over generation may serve citizens living in a built-up area. Although very simple, this initiative brings citizens close to each other and relevantly joins them in a process of social development.

3. Wind Energy Systems by
FredeBlaabjerg, Ke Ma Proceedings of
the IEEE( Nov. 2017)
Wind power now represents a major and growing source of renewable energy. Large wind turbines (with capacities of up to 6-8 MW) are widely installed in power distribution networks. Increasing numbers of onshore and offshore wind farms, acting as power plants, are connected directly to power transmission networks at the scale of hundreds of megawatts. As its level of grid penetration has begun to increase dramatically, wind power is starting to have a significant impact on the operation of the modern grid system. Advanced power electronics technologies are being introduced to improve the characteristics of the wind turbines, and make them more suitable for integration into the power grid. Meanwhile, there are some emerging challenges that still need to be addressed.

This paper provides an overview and discusses some trends in the power electronics technologies used for wind power generation. First, the state-of-the-art technology and global market are generally discussed. Several important wind turbine concepts are discussed, along with power electronics solutions either for individual wind turbines or for entire wind farms. Some technology challenges and future solutions for power electronics in wind turbine systems are also addressed.

4. Wind Energy Scenario and Potential in India by Rahu R. Gunjker, BhupendraDeshmukhProceedings of the IEEE, Published May 2016

India has the fifth-largest power generation portfolio worldwide. The country transitioned from being the seventh-largest energy consumer in the world a. This rapid growth of power capacity and a subsequent rise in demand can be attributed to several factors: Economic growth and increasing prosperity, growing rate of urbanization, rising per capita energy consumption, widening access to energy in the 
country, and also in recent years, India's energy consumption has been increasing at a relatively fast rate due to population growth and economic development. Rapid urbanization and improving standards of living for millions of Indian households, the demand is likely to grow significantly. In order to increase the energy demand day by day. We know that electrical energy generation depend on the fusel fuel. Now a day's availability of fossil fuel is depleted from our country and as well as worldwide

5. Highway Power Generation using Low Cost Vertical Axis Wind Turbine [VAWT] by Vinit .V. Bidi ${ }^{1}$, Devendrappa .M. $\mathrm{K}^{2}$, Chandan .S .P $\mathbf{P}^{3}$, Arun .J. $\mathbf{P}^{4}$, Maruthi .G. $\mathrm{V}^{5}$ Proceedings of the IEEE, published June 2017

In this paper the fabrication of prototype model of Savonious type Vertical Axis Wind Turbine (VAWT) is made using easily available materials like, front wheels of bicycle with ball bearing, half cut PVC pipes, wooden base etc. The CADD model of the VAWT is prepared. This VAWT is placed in the medians of highway. The vehicles from both sides of medians accelerate the wind thus increasing its kinetic energy which forces the turbine blades to rotate in clock wise direction. This drives the rotor which is connected to a DC generator, thus producing electricity. The effort is made to produce electricity at low cost. This electricity can be used for multiple applications like smart highway system, toll booths, highway lightening, etc. This VAWT also acts as a barrier for high beam focus lights emitted by vehicles from opposite lanes, thus reducing the risks of accidents

\section{Efficient Utilization of Waste Heat to Electrical Energy for Real-Time Applications by PallaviKorde ; VijayaKambleProceedings of the IEEE, published July 2018}

With the development of technology, human efforts are reduced, but the energy consumption has increased. In this paper, the electrical energy is generated from waste heat energy with the help of thermoelectric cooler (TEC) module. Depending on the temperature difference applied to the module, electricity is generated. To charge real-time applications, the generated electric potential is uplifted with the help of conversion circuit practically. It also gives the information about the thermoelectricity and its effects, thermoelectric (TE) materials, internal structure of TE module, comparison between TE modules, use of TEC as a thermoelectric generator and the implementation of the design to charge various real-time applications.

\section{Experimental analysis of thermoelectric generator using solar energy by Y. Jeyashree ; A. Vimala Juliet ; A. Alen Joseph, Proceedings of the IEEE Published on 12 January 2015}

In this paper, the performance of a $4 \times 4$ $\mathrm{cm}^{2}$ Bismuth Telluride based thermoelectric generator with 126 thermocouples connected in series is analyzed experimentally under different environmental conditions. The hot junction of the thermoelectric generator is exposed to solar and candle heat and the cold side is exposed to atmosphere. With the hot junction temperature of $53^{\circ} \mathrm{C}$ and cold junction temperature of $32^{\circ} \mathrm{C}$, the output voltage, current and power are measured as $0.35 \mathrm{~V}, 0.042 \mathrm{~A}$ and $0.014 \mathrm{~W}$ respectively. The hot junction of the thermoelectric generator is then exposed to solar concentrator heat and the cold side is exposed to ice. With the hot junction temperature of $100.2^{\circ} \mathrm{C}$ and cold junction temperature of $2.9^{\circ} \mathrm{C}$, the output voltage, and power are measured as $2.96 \mathrm{~V}, 0.1083 \mathrm{~A}$ and $0.319 \mathrm{~W}$ respectively. The power output is increased by $30.5 \%$. The power density is $2.11 \mu$ $\mathrm{Wcm}^{\circ} \mathrm{C}^{-2}$.

\section{Piezoelectric Micro Power Generator for Energy Harvesting by R. Sood, Y.B. Jeon, J.-h. Jeong and S.G. Kim, Proceedings of the IEEE published on 25 may 2018}

A thin film lead zirconated titanitePb(Zr,Ti)O3 (PZT), power generating device is developed. It is designed to resonate at specific vibrational frequencies from an ambient, vibrational energy source, thereby creating electrical energy via the piezoelectric effect. The energy harvesting device uses the piezoelectric d33 mode and is fabricated with three mask steps. Our cantilever device was designed to have a flat structure with a proof 
mass added to the end. A method for controlling the bowing curvature of the cantilever was applied by modulating the residual stress and elastic properties of the composite beam. The top electrode of $\mathrm{Ti}$ and $\mathrm{Pt}$ was patterned into an interdigitated shape on top of the sol-gel-spin coated PZT thin film in order to employ the d33 mode of the piezoelectric.

This d33 mode design can generate at least a 20 times higher voltage than that of the d31 mode design. The device was mechanically excited by base shaking experiments, which revealed that our device has three resonance modes. The base-shaking experiments at the first resonant frequency $(13.9 \mathrm{kHz})$ demonstrated that the generated charge is proportional to the tip displacement of the cantilever with an approximate linearity coefficient of $4.14 \mathrm{pC} / \mu \mathrm{m}$. The total system can deliver $1 \mu \mathrm{W}$ of continuous electrical power to a $5.2 \mathrm{M} \Omega$ resistive load at $2.4 \mathrm{~V}$ DC. The corresponding energy density is $0.74 \mathrm{~mW}$ $\mathrm{h} / \mathrm{cm} 2$, which compares favorably to current chemical batteries (i.e. lithium ion). We expect the optimized design to generate a much higher power level than we have now by targeting and harvesting from lower frequency vibrations.

9. Power sharing of parallel operated DCDC converters using current-limiting droop control by A.-C. Braitor, G. C. Konstantopoulos and $\mathrm{V}$. Kadirkamanathan, Proceedings of the IEEE Published on jan 2017

In this paper, a nonlinear current-limiting droop controller is proposed to achieve accurate power sharing among parallel operated DC-DC boost converters in a DC microgrid application. In particular, the recently developed robust droop controller is adopted and implemented as a dynamic virtual resistance in series with the inductance of each DC-DC boost converter. Opposed to the traditional approaches that use small-signal modeling, the proposed control design takes into account the accurate nonlinear dynamic model of each converter and it is analytically proven that accurate power sharing can be accomplished with an inherent current limitation for each converter independently using input-to-state stability theory.
When the load requests more power that exceeds the capacity of the converters, the current-limiting capability of the proposed control method protects the devices by limiting the inductor current of each converter below a given maximum value. Extensive simulation results of two paralleled DC-DC boost converters are presented to verify the power sharing and current-limiting properties of the proposed controller under several changes of the load.

\section{METHODOLOGY}

1. Initially we studied hardware components for the resource availably required for project.

2. Fixing the thermoelectric generators to back side of the solar panel to generate power from the heat loss of the solar panels by giving Colling on the other side of the thermo electric generators.

3. Connecting piezo transducers in seriesparallel connection to get the desired voltage output for the load in the roads to get motion for the transducers.

4. Installation of the vertical wind turbine with shaft and dynamo connection in the divider of the roads.

5. Checking the voltage of the solar panels, thermoelectric generators, piezo transducers and vertical wind axis turbine.

6. Connecting all these power generating sources to the booster circuit to step up the voltage and regulator circuit.

6. After these we connect these sources to the battery.

\section{IMPLEMENTATION}

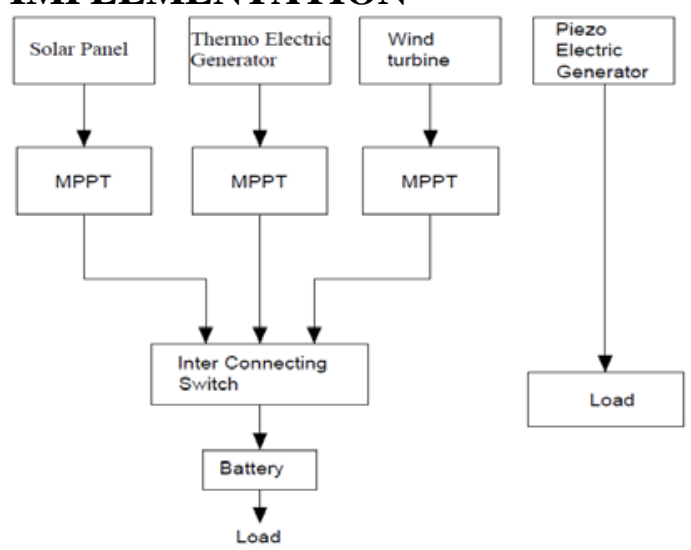

Figure4: Block diagram of module 
In our project we are using solar panels, thermoelectric generators, piezoelectric transducers and vertically wind axis turbine. The designs of the components were has bellows.

\section{Design of Solar panels}

Model name: Solar panel-MS 1220

Voltage at open circuit (Voc): 21 Volts

Short circuit (Isc): 1.36 Amps

Maximum voltage (Vm): 20.1 Volts

Maximum current (Im): 1.16 Amps

Maximum power (Pmax): 20 Watt

Length: $30 \mathrm{~cm}$

Width: $32 \mathrm{~cm}$

Maximum Operating temperature: $150 \mathrm{C}^{0}$

Design of thermo electric generators

Model name: TEC1-12706

Length: $3.8 \mathrm{~cm}$

Width: $3.8 \mathrm{~cm}$

Internal resistance: $1.98 \mathrm{ohm}+/-10 \%$

Voltage: 6V.

Maximum voltage (Vmax): 12V

Imax: 4A.

Type: Cooling cells

Usage: refrigerator, warmer.

Design of piezoelectric transducers

Material: Steel

Dimensions: $1 \mathrm{x} 2 \mathrm{cms}$

Weight: 20gm

Voltage: 10 Volts/cm

Design of vertically wind axis turbine

Length of wing blades:

Angle of each blades: $45^{\circ}$

DC generator

Rated voltage: DC $12 \mathrm{~V}$

Speed no load: 3000PRM

Output power: $2 \mathrm{~W}$

Design of Booster circuit

Assume $\mathrm{P}=100 \mathrm{~W}, \mathrm{Vin}=5 \mathrm{~V}, \mathrm{~V}_{\mathrm{o}}=20 \mathrm{~V}, \mathrm{~F}_{\mathrm{s}}=25 \mathrm{KHz}$

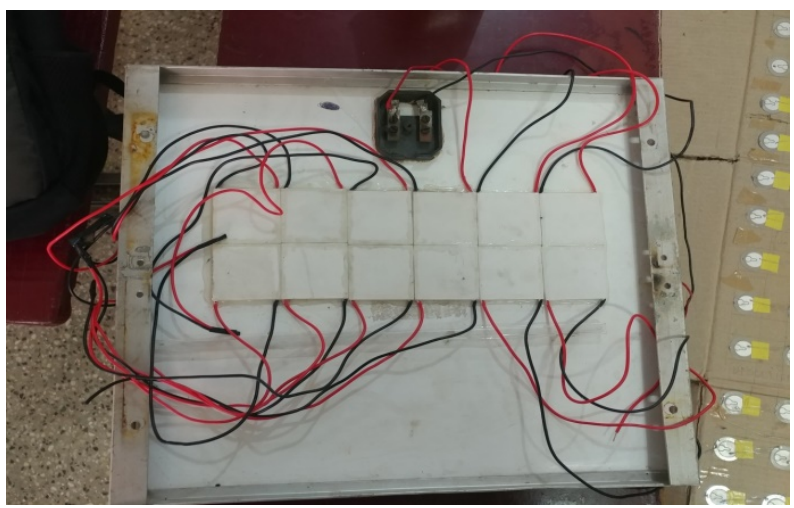

Duty ratio $=1-\left(\mathrm{V}_{\mathrm{s}} / \mathrm{V}_{\mathrm{o}}\right) * \dot{\eta}$ $=1-(5 / 20) * 1$
$=0.75$.

1. $\mathrm{L}=\mathrm{V}_{\mathrm{s}}(\min ) * \mathrm{D} / \mathrm{F}_{\mathrm{s}} * \Delta \mathrm{I}_{1}$

$=(5 * 0.75) /\left(25 * 10^{3} * 0.3\right)$

$\Delta \mathrm{I}_{\mathrm{l}}$ is from

$20-40 \%$, let it be $30 \%$

$=4.224 * 10^{-6}$ Henry

$\mathrm{P}=\mathrm{I}_{\mathrm{S}} * \mathrm{~V}_{\mathrm{S}}=\mathrm{I}_{\mathrm{O}} * \mathrm{~V}_{\mathrm{o}}$

$100=\mathrm{I}_{0} * 5$

$\mathrm{I}_{\mathrm{o}}=5 \mathrm{~A}$

2. $\mathrm{C}=\mathrm{I}_{\mathrm{o}}(\max ) * \mathrm{D} / \mathrm{F}_{\mathrm{s}} * \Delta \mathrm{V}_{\mathrm{C}} \mathrm{V}_{\mathrm{c}}=\mathrm{V}_{\mathrm{o}}$ $=20 * 0.75 /\left(25 * 10^{3} * 0.01 * 20\right)$

$\Delta \mathrm{V}_{\mathrm{c}}=1 \%-5 \%$

$\mathrm{C}=3 * 10^{-3}$ farad

\section{Design of LM317 Regulator}

The LM317 is designed such that $\mathrm{I}_{\mathrm{ADJ}}$ is very small and constant with lineand load changes. The maximum value of adjustment pin current $\mathrm{I}_{\mathrm{ADJ}}$ is $100 \mu \mathrm{A}$.

Where $\mathrm{I}_{1}=\mathrm{V}_{\mathrm{REF}} / \mathrm{R}_{1}$

$$
\mathrm{V}_{\mathrm{o}}=\mathrm{R}_{1} \mathrm{I}_{1}+\mathrm{R}_{2}\left(\mathrm{I}_{1}+\mathrm{I}_{\mathrm{ADJ}}\right)
$$

$\mathrm{R}_{1}=$ current $\left(\mathrm{I}_{1}\right)$ set resistor

$\mathrm{R}_{2}=$ current $\left(\mathrm{V}_{\mathrm{o}}\right)$ set resistor

$\mathrm{V}_{\mathrm{o}}=\mathrm{V}_{\mathrm{REF}}\left(1+\mathrm{R}_{2} / \mathrm{R}_{1}\right)+\mathrm{I}_{\mathrm{ADJ}} \mathrm{R}_{2}$

$\mathrm{V}_{\mathrm{REF}}=1.25 \mathrm{~V}=$ reference voltage between the output and adjustment terminals

$\mathrm{V}_{\mathrm{o}}=1.25\left(1+\mathrm{R}_{2} / \mathrm{R}_{1}\right) \quad \mathrm{R}_{1}=400 \Omega \quad \mathrm{R}_{2}=3600$

$\Omega$

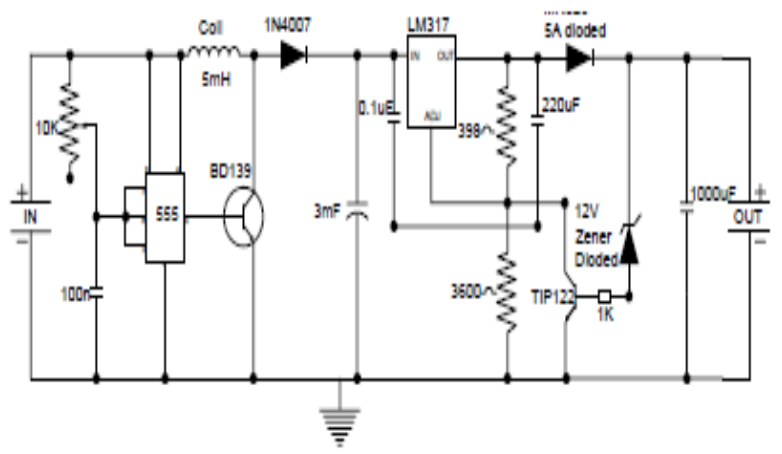

Figure4.7 regulator circuit diagram

4.2 EXPERIMENTAL SETUP

5.1 Solar panel with Dual axis tracking

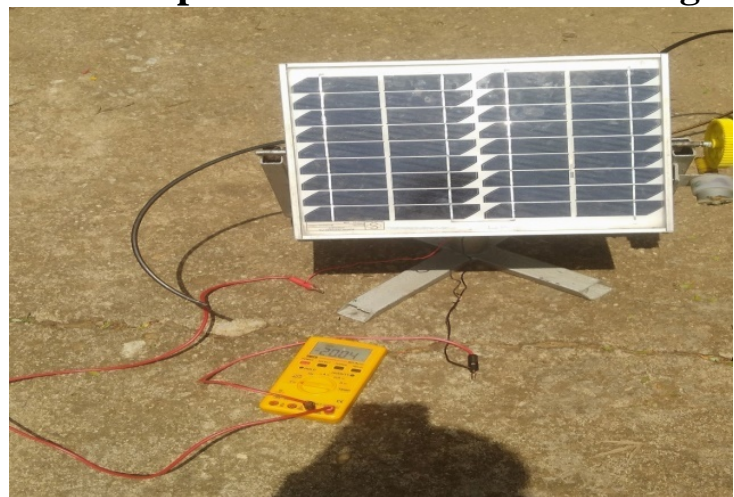




\section{Figure:5.1 Solar panel}

The Solar panels has Solar cells of thirty two numbers are connected in series. Ratings of 0.75 volts, 1 amps of each cell. Total ideal Voltage of 24 volts, current of 1Amps of the module. Practical voltage that we are getting from the solar panel of 21 volts and 0.5 Amps on load condition.

Since all conventional solar panel are fixed in particular position but as the sun direction changes the power generated will also varies, it might be low or high. So to get maximum power from the panels, we are going for the dual axis solar panel. In dual axis it will sense the light intensity on any direction accordingly it will move the panel to the corresponding direction with the help of motor, which will be energised by any one of the strip out of four solar strips which are using in dual axis.

In dual axis we are using four solar strips of ratings are 12 volts,2Watt and 0.2Amps of each cell respectively. These strips are used for the solar tracking in dual axis mode to improve efficiency of power generation.

\section{Thermo electric generators}

A thermoelectric module is a circuit containing thermoelectric materials which generates electricity from heat directly. A thermoelectric module consists of two dissimilar thermoelectric materials joined at their ends: an n-type (negatively charged), and a p-type (positively charged) semiconductor. A direct electric current will flow in the circuit when there is a temperature difference between the ends of the materials.

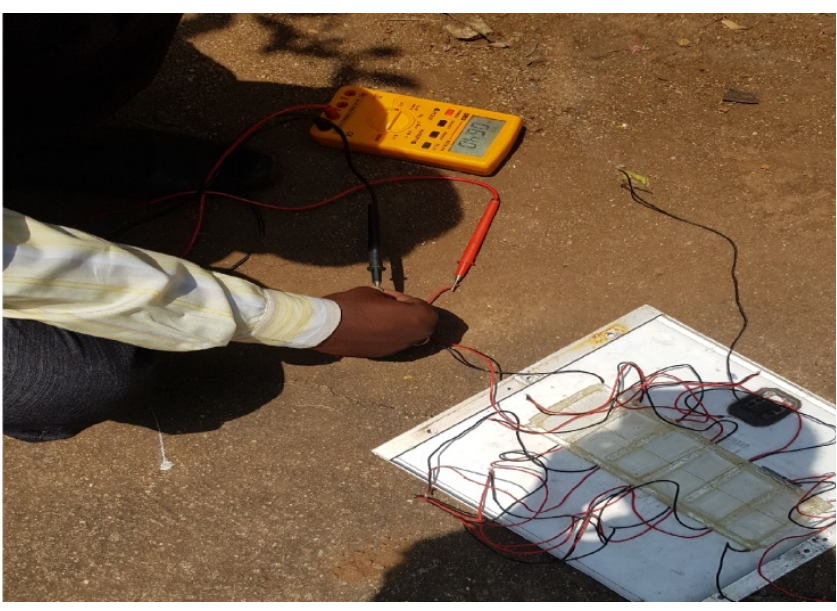

Figure 5.2:Thermo electric generators with output

Thermo electric generator are fixed behind the solar panel, to utilize the waste heat energy, that have been dissipating from the panel. Its maximum allowable heating temperature is of $138^{\circ} \mathrm{C}$ and minimum heating temperature of $30^{\circ}$ $\mathrm{C}$ on one side of TEC.

The cooling temperature ranges from $-5^{0} \mathrm{C}$ to $15^{\circ} \mathrm{C}$, which has to be given on another side of TEC to generate a DC Power.Here in this project we are using twelve number of thermo electric generators, each TEC are connected in series to get a minimum voltage of 5 volts. Maximum and minimum current ratings are 0.75 Amps to 6 Amps respectively.

The TEC's are fixed with the help of araldite epoxy adhesive behind the solar panel. For cooling system, we are using the polyvinyl transparent plates to supply the cooling water on another side of TEC.Here the cold water is continuosly supplying, to get proper cooling on one side of a TEC.

Thermoelectric materials generater power directly from heat by converting temperature difference into electrical voltage. This materials must have both high electrical conductivity and low thermal conductivity to be a good thermo electric material having low thermal conductivity ensures that when one side made hot the other side stay cold which helps to generate a large volatage while in tempature gradient. The measure of magnitude of electrons flow in response of temperature difference across that material is given by the Seebeck coefficient

\section{Piezoelectric Transducer disc}

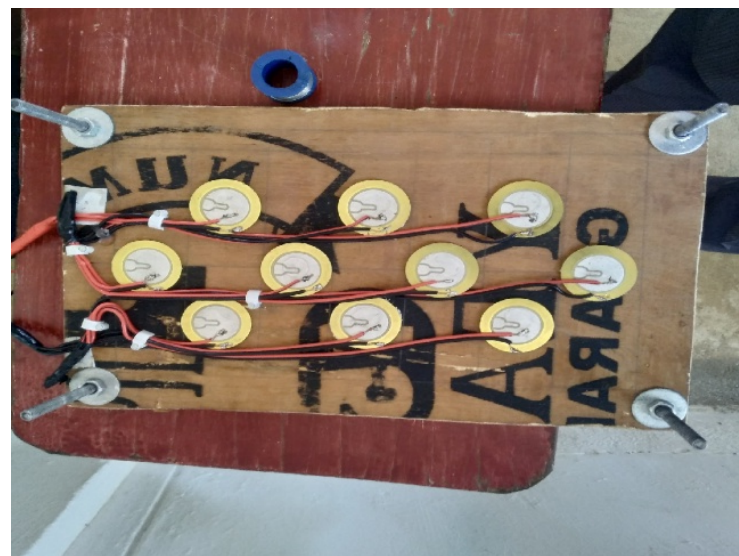

Figure 5.3(a) Piezoelectric Transducer discs

The piezoelectric transducers work on the principle of piezoelectric effect. When mechanical stress or forces are applied to some 
materials along certain planes, they produce electric voltage. This electric voltage can be measured easily by the voltage measuring instruments, which can be used to measure the stress or force.

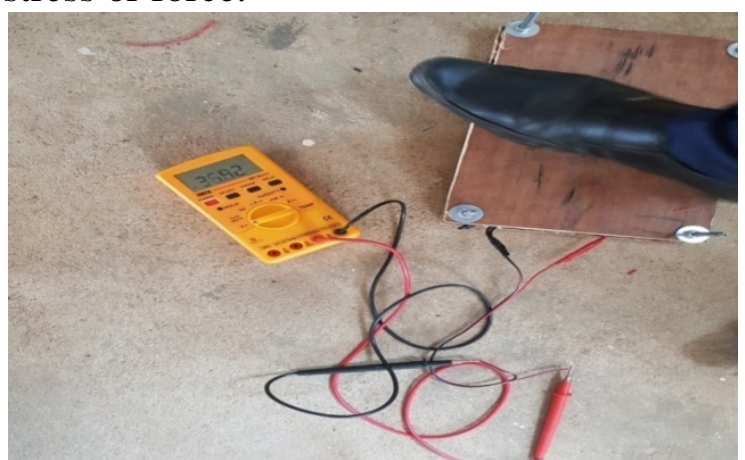

Figure 5.3(b) Piezoelectric Transducer output

The physical quantities like stress and force cannot be measured directly. In such cases the material exhibiting piezoelectric transducers can be used. The stress or the force that has to be measured is applied along certain planes to these materials. The voltage output obtained from these materials due to piezoelectric effect is proportional to the applied stress or force. The output voltage can be calibrated against the applied stress or the force so that the measured value of the output voltage directly gives the value of the applied stress or force.

In this project we are using thirty nine piezoelectric transducer disc's. which are connected in series-parallel connection, so that we can get enough desired voltage and current to power up the load from piezo's.

Since the piezo electric transducer cannot supply or generate the power continuously unless the mechanical stress is applied on it. Here in this project the mechanical forces are generated by humans since the piezoelectric disc's are placing on a foot path. So depends upon the number of humans, amount of stress is applied, by walking on the foot path it will generate power.

\section{Vertical axis wind turbine}

Wind is caused due to uneven heating of earth's surface, atmosphere, irregularities of earth's surface and rotation of the earth about its own axis. The amount of wind flow depends on various factors such as earth's rotation speed and difference in temperature of places. Energy produced by this blowing wind is called as wind energy.
Therefore power generation with the help of non-conventional resource such as wind is increasing day by day and this type of power generation is very clean and safe.

The wind turbines are basically of two types

1) Horizontal axis wind turbine (HAWT).

2) Vertical axis wind turbine (VAWT).

HAWT has successfully evolved in making of electricity from wind. However, recently working on VAWT has also been started due to its additional advantage over HAWT such as it does not require yaw mechanism because it can produce power independent of wind direction. VAWT can be produced at low cost then HAWT and also affordable maintenance cost.

1) Savonious vertical axis wind turbine

2) Darrieus vertical axis wind turbine

3) Giro mill

The aim of the project is to utilize the maximum amount of wind energy and hence highway is selected as the installation site. The wind turbine will be placed in divider so that the tangential acting airflow from both sides of the road due to moving vehicle will help the turbine to rotate. The variation of blade angle is made so as to get the maximum output and blades are then fixed. Savonius rotor is a vertical axis wind turbine which is characterized as cheaper, simpler in construction and low speed turbine.

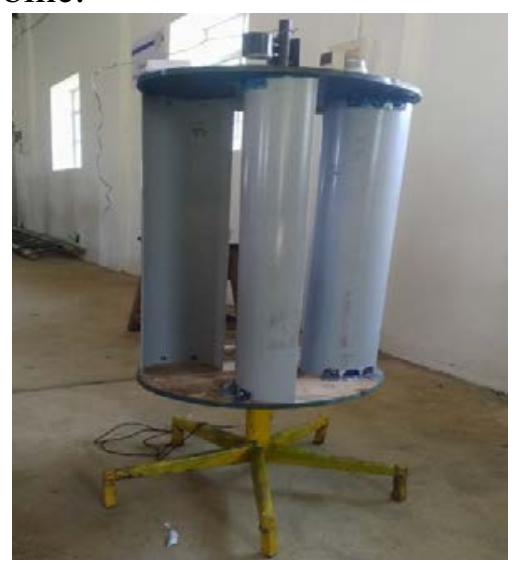

Figure 5.4(a) Vertical axis wind turbine

In vertical axis wine turbine, they accept the wind from any direction, thus eliminating the need for re-orienting towards the wind. The vertical axis wind turbine works due to the differences in forces exert on each blade.

\begin{tabular}{|l|l|l|}
\hline $\begin{array}{l}\text { Hot side } \\
\text { temperature }\left(\mathrm{C}^{0}\right)\end{array}$ & $\begin{array}{l}\text { Cold side } \\
\text { temperature }\left(\mathrm{C}^{0}\right)\end{array}$ & Voltage(Volts) \\
\hline 29 & 23 & 3.5 \\
\hline 32 & 24 & 4.8 \\
\hline 33 & 23 & 5.6 \\
\hline 35 & 24 & 6.1 \\
\hline
\end{tabular}

DOI: 10.21276/ijcesr.2019.6.6.22 
In vertical axis wind turbine, wings are made up of PVC pipe which have been cutted vertically and fixed to a four way junction box through a hollow pipe. The main vertical pipe is then connected to a primary rotational drive. The primary rotational drive consists of a hub which will be welded to a gear.

Dynamo will be fixed to one of the leg of a stand and dynamo shaft end will be connected to a pre wheel. Main gear and pre wheel connected through chain.

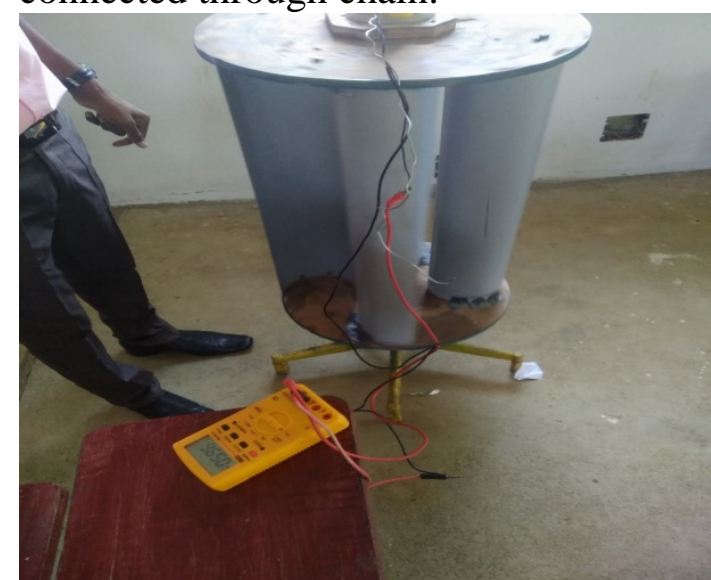

Figure 5.4(b) Vertical axis wind turbine

This vertical axis wind turbine will be installing, on high way path divider. So the vehicles will be moving on both sides of high ways, due to the motion of vehicles velocity of wind will suddenly increases and rotates the turbine blades. Due to this, turbine shaft will rotates the main gear is connected to a dynamo shaft, which will generates power through a rotation of wind turbines.

\section{RESULT AND ANALYSIS}

Solar Panel Outputs

\begin{tabular}{|l|l|l|l|}
\hline $\begin{array}{l}\text { Time(H } \\
\text { ours) }\end{array}$ & $\begin{array}{l}\text { Voltage( } \\
\text { Volts) }\end{array}$ & $\begin{array}{l}\text { Current(Am } \\
\text { peres) }\end{array}$ & $\begin{array}{l}\text { Power(W } \\
\text { atts) }\end{array}$ \\
\hline $\begin{array}{l}10.00 \mathrm{~A} \\
\mathrm{M}\end{array}$ & 15.4 & 0.55 & 8.47 \\
\hline $\begin{array}{l}11.00 \mathrm{~A} \\
\mathrm{M}\end{array}$ & 16.2 & 0.52 & 8.424 \\
\hline $\begin{array}{l}12.00 \mathrm{P} \\
\mathrm{M}\end{array}$ & 17.8 & 0.5 & 8.9 \\
\hline $1.00 \mathrm{PM}$ & 18.9 & 0.48 & 9.07 \\
\hline 2.00PM & 19.3 & 0.45 & 8.68 \\
\hline 3.00PM & 18.6 & 0.51 & 9.48 \\
\hline 4.00PM & 18.3 & 0.53 & 9.69 \\
\hline
\end{tabular}

\begin{tabular}{|c|c|c|c|}
\hline $\begin{array}{c}\text { Speed } \\
\text { (RPM) }\end{array}$ & Voltage(Volts) & Current(Amps) & $\begin{array}{c}\text { Power } \\
\text { (Watts) }\end{array}$ \\
\hline 547 & 2.7 & $30 \mathrm{~mA}$ & 0.0081 \\
\hline 623 & 4.2 & $26 \mathrm{~mA}$ & 0.01 \\
\hline 732 & 5.9 & $19 \mathrm{~mA}$ & 0.011 \\
\hline 824 & 7.2 & $17 \mathrm{~mA}$ & 0.012 \\
\hline
\end{tabular}

Graph for the vertically wind axis turbine

\begin{tabular}{|l|l|}
\hline Pressure $\left(\mathrm{N} / \mathrm{M}^{2)}\right.$ & Voltage(volts) \\
\hline $10^{2}-10^{4}$ & 20.3 \\
\hline $10^{3}-10^{5}$ & 37.4 \\
\hline $10^{4}-10^{6}$ & 48.5 \\
\hline $10^{5}-10^{7}$ & 55.3 \\
\hline
\end{tabular}

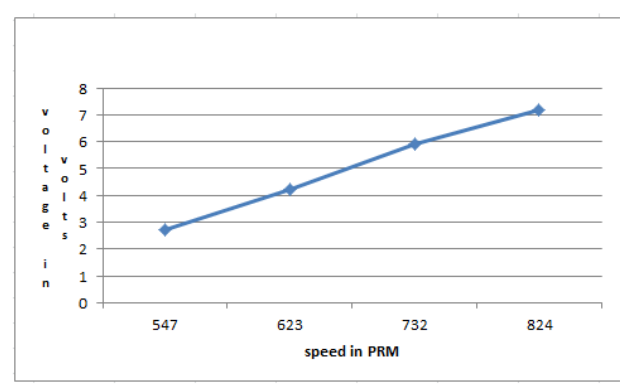

Piezoelectric transducers

Piezoelectric transducers 


\section{ADVANTAGES}

- They are practically inexhaustible sources of energy and contribute to reducing the dependence on depletable conventional energy sources.

- Renewable energy sources are sustainable and abundant in nature.

- These sources require less maintenance than traditional generators.

- Renewable energy sources produce little or no waste products such have carbon dioxide or other chemical pollutants.

- Renewable energy makes real economic sense because it is a cheaper alternative to most traditional sources of energy.

\section{DISADVANTAGES}

- Many forms of renewable energy are location specific.

- It is difficult to generate the electricity that is as large as those produced by traditional fossil fuel generators.

- Renewable energy often relies on the weather for its source of power.

- Setting up renewable energy generation facilities requires a huge financial outlay.

- Though available freely in nature the cost of harnessing energy from non-conventional sources is generally high

\subsection{APPLICATIONS}

- We can install the vertical wind axis turbine in the divider of the highways to get the maximum output.

- We can minimize the heat loss from the solar panels by installing the thermo electric generators in back side of solar panels. So we can generate power from both the sources.

- Piezoelectric transducers are installed in footpath of dense areas. So power can be generated easily.

- By installing all these resources in the city we can able to generate power for the city and reduces the transmission lines and losses.

\section{CONCLUSION}

- Smart Energy Information Management System will be controlled by redistributing demand which reduce demand - supply Mismatch significantly

- Smart power generation with renewable energy resources can minimize the transmission losses.
- The distribution systems will have advanced metering, robust communications capability, extensive automation, distributed generation, and distributed storage. Through the integrated use of these technologies, Smart Grids will be able to self heal, provide high reliability and power quality, be resistant to cyber attacks, operate with multi-directional power flow, increase equipment utilization, operate with lower cost, and offer customers a variety of service choices.

- Smart appliances should be used in conjunction with smart grid for reducing the peak demand. Real time information feedback regarding peak load conditions sent to smart appliances at customer site

- The proposed architecture provides numerous other benefits like better demand forecasting, providing information for trading and investment decisions.

- Smart grid used with smart appliances has the potential to revolutionize the energy management as it reduces and re- distribute demand automatically.

\section{FUTURE SCOPE}

- In this project, we are installing the thermoelectric generators on back side of the solar panel. The efficiency of that can be improved in future.

- As discussed vertically wind axis turbine can be installed in the highways.

- With the sources like renewables at time to come, it completely decarbonizes of the power generation system and ecofriendly.

- Piezoelectric transducers can be installed in the populated area with the advancement in the technology.

- By using smart power genwration from renewable energy resources we can minimize the transmission losses in power system.

\section{BIBLIOGRPAHY}

1. The Impacts of Storing Solar Energy in the home to reduce reliance on the utility by Robert L. Fares* and Michael E. Webber Proceedings of the IEEE: Published: 30 January 2017

2. Solar Energy and PV Systems in Smart Cities by Daniele Menniti ${ }^{1}$, Angel A. Bayod-Rújula ${ }^{2}$, Alessandro Burgio ${ }^{3}$, Diego 
A. L. García ${ }^{4}$ Proceedings of the IEEE Published 9 July 2017

3. Wind Energy Systems by FredeBlaabjerg, Ke Ma Proceedings of the IEEE

Nov. 2017 )

4. Wind Energy Scenario and Potential in India by Rahu R. Gunjker, BhupendraDeshmukhProceedings of the IEEE, Published May 2016

5. Highway Power Generation using Low Cost Vertical Axis Wind Turbine [VAWT] by Vinit .V. Bidi ${ }^{1}$, Devendrappa .M. $\mathrm{K}^{2}$, Chandan .S .P ${ }^{3}$, Arun .J. $\mathrm{P}^{4}$, Maruthi .G. V ${ }^{5}$ Proceedings of the IEEE, published June 2017

6. Electricity generation using thermoelectric generator - TEG by Messias A. A. Faria, Elder G. Domingues, Pedro H. G. Gomes, Proceedings of the IEEE Published 23 July 2015

7. Experimental analysis of thermoelectric generator using solar energy by Y. Jeyashree ; A. Vimala Juliet ; A. Alen Joseph, Proceedings of the IEEE Published on 12 January 2015

8. Piezoelectric Micro Power Generator for Energy Harvesting by R. Sood, Y.B. Jeon, J.-h. Jeong and S.G. Kim, Proceedings of the IEEE published on 25 may 2018

9. "Key World Energy Statistics (2018)" (PDF). International Energy Agency. 2018. p. 14.

10. Ipsos Global @dvisor (23 June 2011). "Global Citizen Reaction to the Fukushima Nuclear Plant Disaster" (PDF).p. 3. Archived from the original(PDF) on 3 December 2011.

11. ^Ellabban, Omar; Abu-Rub, Haitham; Blaabjerg, Frede (2014). "Renewable energy resources: Current status, future prospects and their enabling technology". Renewable and Sustainable Energy $\quad$ Reviews39: 748-764 [749]. doi:10.1016/j.rser.2014.07.113.

12. Jump up to:vbhbhghjgyhjgk [;poip]o= /'REN21 (2010). Renewables 2010 Global StatusReport 